\title{
Physio-pathology of induced endotoxaemia in bovine and its treatment regimen
}

\author{
Irtiza Nabi ${ }^{1}$, Digvijay Singh ${ }^{1}$, Naresh Kumar $\operatorname{Sood}^{2}$ \\ ${ }^{1}$ Department of Veterinary Physiology and Biochemistry, College of Veterinary Science, Guru Angad Dev Veterinary and Animal \\ Sciences University, Ludhiana, India \\ ${ }^{2}$ Department of Veterinary Pathology, College of Veterinary Science, Guru Angad Dev Veterinary and Animal Sciences University, \\ Ludhiana, India \\ Email: digvijay231@rediffmail.com
}

Received 30 September 2013; revised 2 November 2013; accepted 18 November 2013

Copyright (C) 2013 Irtiza Nabi et al. This is an open access article distributed under the Creative Commons Attribution License, which permits unrestricted use, distribution, and reproduction in any medium, provided the original work is properly cited.

\begin{abstract}
Endotoxic shock was induced in five apparently healthy male buffalo calves by i.v infusion of Escherichia coli endotoxin at $5 \mathrm{microgram} / \mathrm{kilogram}(\mu \mathrm{g} / \mathrm{Kg})$ body weight/hour (BW/hr) for 3 hours. Endotoxin infusion caused clinical signs of restlessness, respiratory distress, snoring, diarrhoea, profuse salivation along with the significant hypoproteinemia, hypoalbuminemia and hypokalemia in all the animals. The animals were observed up to day 4 or death, whichever was earlier. The treatment with one time intravenous infusion of hypertonic saline solution @ 4milliliter/Kilogram body weight $(\mathrm{ml} / \mathrm{Kg} \cdot \mathrm{BW})$, dextran-40@10 ml/Kg·BW, flunixin meglumine @ $1.1 \mathrm{milligram} / \mathrm{Kg} \cdot \mathrm{BW}(\mathrm{mg} / \mathrm{Kg} \cdot \mathrm{BW})$ and blood @ $20 \mathrm{ml} / \mathrm{Kg} \cdot \mathrm{BW}$ to these animals alleviated the clinical signs and significantly raised the circulating glucose level at 4.5 and $5.5 \mathrm{hrs}$. The treatment led to survival of three of the five endotoxemic buffalo calves. The significant hypoproteinemia, hypoalbuminemia, hypokalemia and hypoglobulinemia continued even after treatment. Gross and histopathologic findings of congestion, haemorrhage, necrosis in vital organs viz., lungs, liver, kidneys, brain and intestines were suggestive of endotoxin induced hypoxia and multi-organ failure. Additionally, emphysema and fibrinous thrombi in microvasculature of lungs were salient histopathological findings indicating terminal respiratory failure in the remaining two dead endotoxemic buffalo calves. From clinical signs, plasma chemistry and pathological lesions, it was concluded that endotoxemia led to a disruption of critical life processes, but a timely and effective treatment could counter these deleterious effects and save precious lives.
\end{abstract}

Keywords: Blood; Buffalo Calves; Dextran-40;
Endotoxemia; Flunixin Meglumine; Hypertonic Saline; Physiology; Pathology

\section{INTRODUCTION}

Endotoxic shock is an acute circulatory failure occurring in the presence of severe infection and represents an imbalance between the body's oxygen demand and supply. It is principally of the distributive type, although cardiogenic and hypovolemic components may also be involved [1]. Endotoxin is an integral component of the outer membrane of gram-negative bacteria and the effects of exposure of host cells to it include the uncontrolled release of cytokines and eicosanoids, kinins and other short, medium and long-term reactants that upset the balance between pro-inflammatory and anti-inflammatory pathways, causing hypotension, disseminated intravascular coagulation, abortion and death [2]. Endotoxemia is a life-threatening inflammatory condition, which can lead to shock, multiple organ failure, suppression of immune system and interferes with wound-healing processes [3].

Despite many limitations, animal models remain essential for the development of new therapeutic regimens of endotoxic shock, which can't be replicated by in-vitro studies [4].

Therefore, the present investigation was planned with the objectives to study the major physio-pathological changes during induced endotoxemia in buffalo calves and the effects of treatment regimen of hypertonic saline solution, Dextran-40, Flunixin meglumine and whole blood infusion on these profiles. The studies could also help in finding suitable therapeutic regimens applicable in other species of animals and man.

\section{MATERIAL AND METHODS}

Five apparently healthy 6-month to one-year-old male 
buffalo calves with body weight range of $70-140 \mathrm{Kg}$ were used in the present investigation. These calves were kept under the good managemental conditions as are practiced at the university dairy farm. All the animals were de-wormed and vaccinated against haemorrhaegic septicemia well before the start of the experiment.

The Endotoxin ${ }^{1}$ was reconstituted by dissolving it in normal saline solution $(0.9 \% \mathrm{NaCl})$ to make a stock solution of $1 \mathrm{mg} / \mathrm{ml}$. Endotoxin concentration of $5 \mu \mathrm{g} / \mathrm{ml}$ was prepared by dissolving $1 \mathrm{ml}$ of stock solution in $199 \mathrm{ml}$ of normal saline to make a total volume $200 \mathrm{ml}$. The endotoxin was then infused intravenously through jugular vein@ $5 \mu \mathrm{g} / \mathrm{kg}$ BW/hr for 3 hours, followed immediately by a rapid infusion of hypertonic saline solution @ 4 milliliter/Kilogram body weight (ml/Kg·BW), dextran40 @ $10 \mathrm{ml} / \mathrm{Kg} \cdot \mathrm{BW}$, flunixin meglumine @ $1.1 \mathrm{milli}-$ gram/Kg·BW (mg/Kg·BW) and blood@20 ml/Kg·BW Body as one time treatment. The HSS had been prepared by dissolving $72 \mathrm{gm}$ of sodium chloride in one liter of double distilled water (7.2\% Nacl aqueous solution) and autoclaved at a pressure of 15 lbs for 20 minutes, 16 - 18 hrs prior to infusion.

The animals were casted in right lateral recumbency on operation table. Before endotoxin infusion, an area over jugular furrow was shaved and disinfected. The local anesthetic Lignocaine (2\%) @ 90 - 120 ml was injected subcutaneously and intra-muscularly before catheterization of the jugular vein and the carotid artery. The blood samples from jugular vein of the experimental buffalo calves were collected in heparin immediately before and after $1.5,2.5,3.5,4.5,5.5,6.5$ hrs of the start of endotoxin infusion, followed by samples at $24 \mathrm{hr}$ of last sample of day 1 , upto $4^{\text {th }}$ day. The following physiological constituents like the plasma total protein, acute phase proteins like albumin, fibrinogen, globulins, alkaline phosphatase, creatinine, glucose, sodium, potassium, calcium and phosphorus were estimated by dry stat clinical chemistry analyser ${ }^{2}$. Plasma fibrinogen was estimated using a portable refractometer by comparing the protein in nonheated plasma and that in the respective sample heated to $56^{\circ}$ to $58^{\circ}$ Celsius for 3 minutes [5]. The data so generated was pooled and analysed with CRD Anova [6]. All the values obtained were compared with the normal preinfusion values within the group. The study design and animal experimental protocols were approved by the Institutional Animal Ethics Committee (IAEC) of the University.

\section{RESULTS AND DISCUSSION}

\subsection{Clinical Signs}

Clinical signs observed due to endotoxemia consisted of

$\overline{{ }^{1} \text { Escherichia coli endotoxin Lyophilized (Phenol extracted) 0111:B4 }}$ lipopolysacharide, SIGMA Chemicals USA.

${ }^{2}$ Dry stat clinical dry chemistry analyser, Johnson \& Johnson, USA. restlessness, respiratory distress, forceful abdominal respiration, diarrhoea and profuse salivation. Three endotoxemic buffalo calves out of five animals survived beyond the observation period, whereas, the remaining two buffalo calves died during the observation period.

\subsection{Clinical Chemistry}

The results of the physiological profiles estimated during present investigation are presented in Table 1 and Figures 1-3.

The normal mean pre-infusion total protein was found to be $6.62 \pm 0.17 \mathrm{~g} / \mathrm{dl}$, which is close to $6.82 \pm 0.24 \mathrm{~g} / \mathrm{dl}$ reported by Sobti et al. (1981) [7], $6.40 \pm 0.19 \mathrm{~g} / \mathrm{dl}$ [8], but lower than $7.54 \pm 0.25 \mathrm{~g} / \mathrm{dl}$ [9]. In the present study, however, a significant $(\mathrm{P}<0.05)$ hypoproteinemia was observed at $3.5 \mathrm{hr}$ after the endotoxin infusion (Figure 1). $[10,11]$ also observed hypoproteinemia on E. coli endotoxin infusion in bovine calves.

The hypoproteinemia as observed in present investigation was perhaps due to increased protein catabolism coupled with decreased ability of anoxic liver to metabolize amino acid to synthesize protein, besides sequestration of plasma proteins into tissues [8].

A significant $(\mathrm{P}<0.05)$ hypoproteinemia continued even after treatment with HSS, Dextran-40, flunixin meglumine and blood at 4.5, 5.5 and 6.5 hrs., which may be attributed to the rapid plasma volume expansion and the redirected splanchnic perfusion following HSS infusion [12]. In fact, the HSS acutely increases the plasma osmolarity and draws intracellular and interstitial water into the vascular space. There was plasma volume expansion of $3 \mathrm{ml}$ for every $1 \mathrm{ml}$ of hypertonic saline infused [13].

The pre-infusion plasma albumin was found to be 2.78 $\pm 0.10 \mathrm{~g} / \mathrm{dl}$, which is similar to $2.70 \pm 0.12 \mathrm{~g} / \mathrm{dl}$ [14] but lower than $3.29 \pm 0.13 \mathrm{~g} / \mathrm{dl}$ and $3.20 \pm 0.19 \mathrm{~g} / \mathrm{dl}[15,16]$. A significant $(\mathrm{P}<0.05)$ hypo-albuminemia was observed throughout the endotoxin infusion (Figure 1). Hypoalbuminemia persisted even after treatment at 4.5, 5.5 and 6.5 hrs. in a previous study [8]. A significant $(\mathrm{P}<0.05)$ hypoalbuminemia in endotoxin infused buffalo calves was also observed [8]. The fall in albumin can be attributed to loss of blood and plasma in tissues, besides diarrhoea, the common manifestations in endotoxic shock. The hypo-albuminemia, in turn, might contribute to hypoproteinemia [15].

The pre-infusion mean plasma fibrinogen recorded was $0.24 \pm 0.04 \mathrm{~g} / \mathrm{dl}$, which is lower than 0.30 to $0.8 \mathrm{gm} / \mathrm{dl}$ [5] and 0.35 to $0.60 \mathrm{~g} / \mathrm{dl}$ [16]. In the present study, only nonsignificant post-infusion alterations in fibrinogen level were observed throughout the experiment (Figure 1).

The normal or pre-infusion mean plasma globulins were found to be $3.54 \pm 0.22 \mathrm{~g} / \mathrm{dl}$, which is close to $3.90 \pm$ $0.39 \mathrm{~g} / \mathrm{dl}$ [14], but higher than $3.24 \pm 0.24 \mathrm{~g} / \mathrm{dl}$ [15], 2.34 $\pm 0.25 \mathrm{~g} / \mathrm{dl}$ [17] and $2.79 \pm 0.13 \mathrm{~g} / \mathrm{dl}$ [18]. In the present 
Table 1. Clinical chemistry (Mean + S.E.) at different stages of endotoxic shock and after treatment with HSS, Dextran-40, Flunixin meglumine and Blood.

\begin{tabular}{|c|c|c|c|c|c|c|c|c|}
\hline \multirow[t]{2}{*}{ Group } & \multicolumn{4}{|c|}{ Endotoxic shock } & \multicolumn{4}{|c|}{ After treatment } \\
\hline & $0 \mathrm{~h}$ & $1.5 \mathrm{~h}$ & $2.5 \mathrm{~h}$ & $3.5 \mathrm{~h}$ & $4.5 \mathrm{~h}$ & $5.5 \mathrm{~h}$ & $6.5 \mathrm{~h}$ & Day2 \\
\hline Total protein(g/dl) & $6.62 \pm 0.17$ & $6.04 \pm 0.39$ & $5.96 \pm 0.23$ & $5.20^{*} \pm 0.21$ & $4.44^{*} \pm 0.28$ & $4.50^{*} \pm 0.16$ & $4.88^{*} \pm 0.07$ & $6.32 \pm 0.39$ \\
\hline Albumin(g/dl) & $2.78 \pm 0.10$ & $2.20^{*} \pm 0.08$ & $2.26^{*} \pm 0.07$ & $1.98^{*} \pm 0.58$ & $1.60^{*} \pm 0.09^{*}$ & $1.58^{*} \pm 0.07$ & $1.78^{*} \pm 0.11$ & $2.54 \pm 0.28$ \\
\hline Fibrinogen(g/dl) & $0.24 \pm 0.04$ & $0.24 \pm 0.04$ & $0.44 \pm 0.19$ & $0.40 \pm 0.09$ & $0.36 \pm 0.04$ & $0.57 \pm 0.27$ & $0.60 \pm 0.22$ & $0.64 \pm 0.20$ \\
\hline Globulins(g/dl) & $3.54 \pm 0.22$ & $3.60 \pm 0.31$ & $3.26 \pm 0.40$ & $2.82 \pm 0.27$ & $2.48^{*} \pm 0.27$ & $2.36^{*} \pm 0.33$ & $2.50^{*} \pm 0.29$ & $3.14 \pm 0.39$ \\
\hline Glucose(mg/dl) & $92.00 \pm 2.17$ & $101.60 \pm 10.64$ & $93.80 \pm 8.26$ & $130.20 \pm 10.18$ & $175.00^{*} \pm 12.17$ & $154.40^{*} \pm 15.20$ & $110.60 \pm 17.33$ & $130.20 \pm 33.44$ \\
\hline Creatinine(mg/dl) & $1.52 \pm 0.15$ & $1.60 \pm 0.14$ & $1.74 \pm 0.18$ & $1.54 \pm 0.09$ & $1.52 \pm 0.10$ & $1.56 \pm 0.10$ & $1.74 \pm 0.23$ & $2.12^{*} \pm 0.29$ \\
\hline Sodium(mmol/l) & $133.60 \pm 2.21$ & $131.60 \pm 2.64$ & $134.40 \pm 1.72$ & $135.40 \pm 1.29$ & $131.20 \pm 2.91$ & $130.00 \pm 3.74$ & $136.00 \pm 2.12$ & $132.60 \pm 2.04$ \\
\hline Potassium(mmol/l) & $3.36 \pm 0.15$ & $2.72^{*} \pm 0.12$ & $2.78^{*} \pm 0.22$ & $2.64 * 0.12$ & $2.40^{*} \pm 0.15$ & $2.38^{*} \pm 0.07$ & $2.46^{*} \pm 0.11$ & $2.92 \pm 0.22$ \\
\hline Calcium(mg/dl) & $9.82 \pm 0.72$ & $8.02^{*} \pm 0.34$ & $7.46^{*} \pm 0.23$ & $6.86^{*} \pm 0.14$ & $6.56^{*} \pm 0.22$ & $6.74^{*} \pm 0.28$ & $7.28^{*} \pm 0.38$ & $7.88^{*} \pm 0.43$ \\
\hline Phosphorus(mg/dl) & $5.16 \pm 0.31$ & $5.14 \pm 0.16$ & $5.02 \pm 0.24$ & $4.92 \pm 0.15$ & $4.58 \pm 0.29$ & $4.66 \pm 0.22$ & $4.68 \pm 0.30$ & $5.74 \pm 0.60$ \\
\hline $\begin{array}{c}\text { Alkaline } \\
\text { Phosphatase(U/l) }\end{array}$ & $63.40 \pm 18.62$ & $70.60 \pm 21.95$ & $71.40 \pm 19.35$ & $78.00 \pm 26.90$ & $78.00 \pm 15.90$ & $74.20 \pm 20.95$ & $84.80 \pm 21.0$ & $77.80 \pm 19.20$ \\
\hline
\end{tabular}

No. of animals in group $=5 ;{ }^{*}$ Significant at $5 \%$ level.

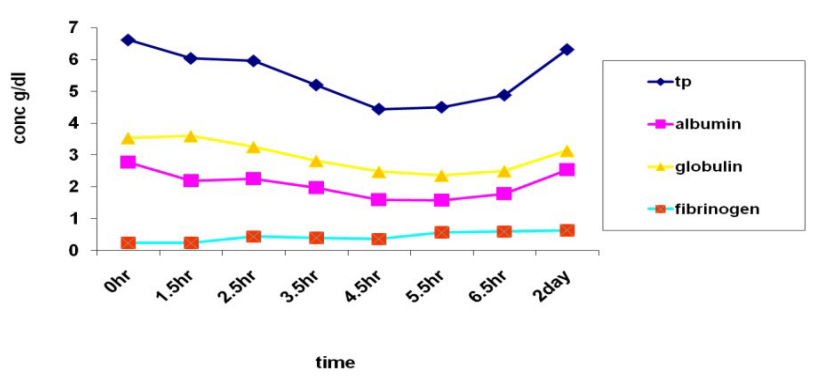

Figure 1. Total protein, Albumin, globulin and fibrinogen during and after endotoxic shock and treatment.

study, buffalo calves did not show any significant change in plasma globulins during endotoxin infusion. After treatment, a significant $(\mathrm{P}<0.05)$ fall in globulins at 4.5, 5.5 and 6.5 hrs. was observed, which may be due to the increased protein breakdown as also reflected by hypoproteinemia, in the present study. The pre-infusion mean plasma creatinine observed was within the physiological range i.e., $1.52 \pm 0.15 \mathrm{mg} / \mathrm{dl}$ [15], which is also close to 1.10 to $1.30 \pm 0.10 \mathrm{mg} / \mathrm{dl}$ [12]. A non-significant variation in plasma creatinine (Figure 2) was observed during the intravenous infusion of the endotoxin. However, plasma creatinine increased significantly after treatment on day 2 of observation in comparison to pre-infusion level. It may probably be due to the protracted endotoxin induced renal damage as observed grossly and histopathologically in the present study.

The normal mean blood glucose observed was $92.00 \pm$ $2.17 \mathrm{mg} / \mathrm{dl}$, which is higher than $67.50 \pm 1.74 \mathrm{mg} / \mathrm{dl}$ and $75.30 \pm 0.97 \mathrm{mg} / \mathrm{dl}$. [14], [8]. In the present study, the plasma glucose level showed a non-significant alteration during i.v. infusion of endotoxin. However, after treatment, a significant $(\mathrm{P}<0.05)$ hyperglycemia at 4.5 and 5.5 hrs. was observed (Figure 3), suggesting probable beneficial effects of Dextran-40, which gets converted creatinine

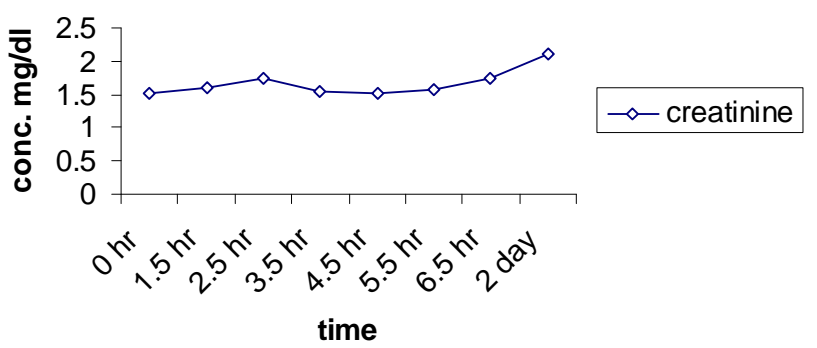

Figure 2. Creatinine during and after endotoxic shock and treatment.

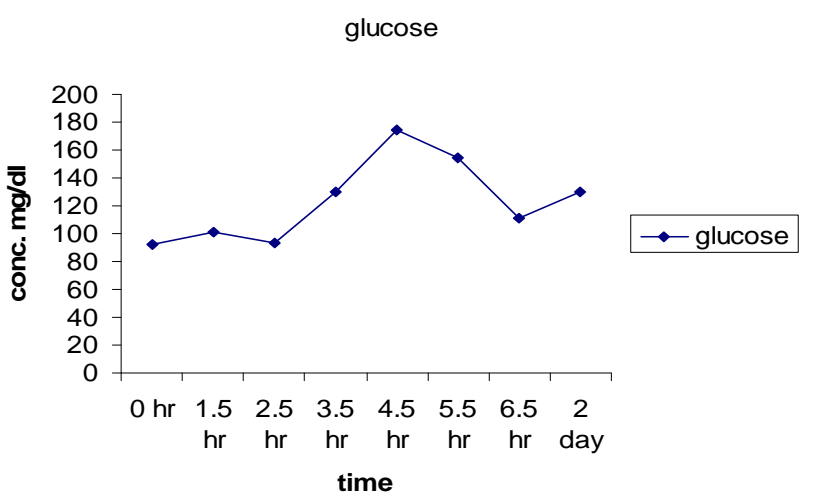

Figure 3. Plasma glucose during and after endotoxic shock and treatment.

into glucose through metabolism in liver. Hyperglycemia may also be due to release of epinephrine due to the stress of catheterization, besides shock.

The pre-infusion mean plasma calcium observed was $9.82 \pm 0.72 \mathrm{mg} / \mathrm{dl}$, which is within the physiological range of $8.7-11.4 \mathrm{mg} / \mathrm{dl}$ [15] and $9.7-12.4 \mathrm{mg} / \mathrm{dl}$ [19]. In the present study, a significant $(\mathrm{P}<0.05)$ hypocalcaemia was observed throughout the experiment as also 
reported previously [20]. The pre-infusion mean plasma phosphorus observed was $5.16 \pm 0.31 \mathrm{mg} / \mathrm{dl}$., which is close to physiological value of $5.6-6.5 \mathrm{mg} / \mathrm{dl}$ [19] and the plasma phosphorus did not show any significant variation during and after the intravenous infusion of endotoxin and the treatment.

The pre-infusion mean plasma sodium observed was $133.6 \pm 2.21 \mathrm{mmol} / \mathrm{l}$, which is close to $136.6 \pm 5.51$ $\mathrm{mmol} / \mathrm{l}$ [16], $134.48 \pm 4.07 \mathrm{mmol} / \mathrm{l}$ [9] and $133.40 \pm 3.19$ $\mathrm{mmol} / \mathrm{l}$ [20]. However, a generalized non-significant increase in sodium was noticed throughout the period of experiment as also recorded in endotoxemic cows [21] and buffalo calves [14], previously. In the present investigation, the mean sodium level at the end of the observation period was almost equal to pre-infusion level. Absence of any significant increase in plasma sodium even after infusion of HSS seems to be advantageous as it makes the infusion of HSS safe [22].

The pre-infusion mean plasma potassium ranged between $3.36 \pm 0.15 \mathrm{mmol} / \mathrm{l}$, which is close to $3.60 \pm 0.2$ $\mathrm{mmol} / \mathrm{l}$ [21] but higher than $2.28 \pm 0.18 \mathrm{mmol} / \mathrm{l}$ [9]. A significant $(\mathrm{P}<0.05)$ hypokalemia was observed at 1.5 , 2.5 and 3.5 hrs. i.e., throughout the endotoxin infusion and even after treatment at 4.5, 5.5 and 6.5 hrs. This fall in potassium level may be regarded as an attempt by the body to sequester potassium as a part of the mechanism, whereby endotoxins promote the release of endogenous pyrogens from leucocytes. Decrease in potassium level could also be attributed to release of histamine during endotoxic shock, which increases the capillary permeability, besides regulating the secretion of adrenaline and noradrenaline together [23]. Hypokalemia after treatment can rather be attributed to rapid volume expansion following HSS infusion [12]. Decrease in plasma levels of sodium and potassium may furthermore be attributed to the greatly diminished active transport of sodium and potassium across the cell membrane [23].

The pre-infusion mean plasma alkaline phosphatase was $63.40 \pm 18.62 \mathrm{U} / \mathrm{l}$, which is lower than $173 \pm 40 \mathrm{U} / \mathrm{l}$ as reported by [12]. A non-significant variation in plasma alkaline phosphatase was recorded throughout the period of observation.

\section{PATHOLOGICAL LESIONS}

Two out of five endotoxemic buffalo calves that died during observation period were subjected to necropsy examination in order to study the gross and histopathological changes.

\subsection{Gross Lesions}

Gross lesions varied from mild to clear cut haemorrhages along with congestion and emphysema in lungs (Figure 4) in both the endotoxemic buffalo calves. In addition, congestion, odema and dilation of intestines (Figure 5), haemorrhages on its mucosal surface as well as in mediastinal lymph nodes and in the gall bladder mucosa were noticed. Severe congestion leading to reddish discoloration of cortex of the kidneys (Figure 6) was conspicuous. The gross lesions were suggestive of toxemia, enteropathy and pulmonary insult accompanying endotoxic shock.

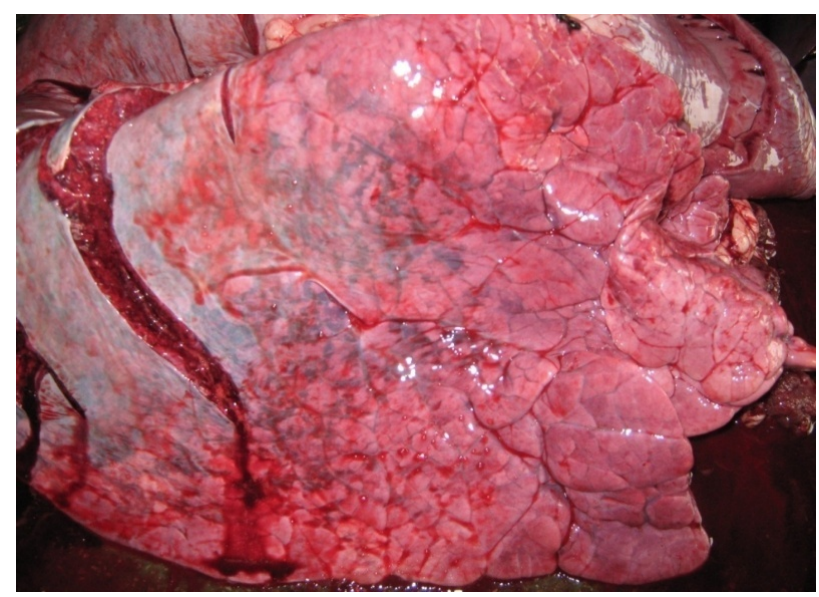

Figure 4. Lung-haemorrhages and emphysema.

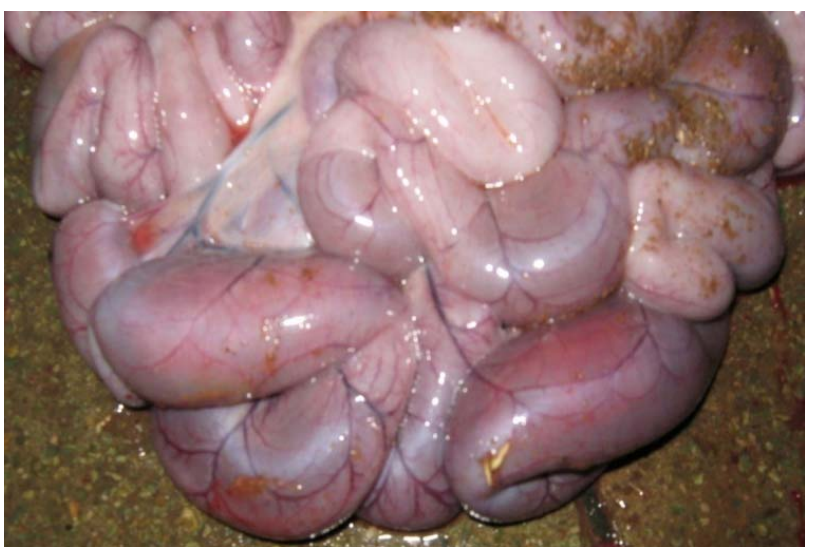

Figure 5. Intestines-congestion, edema and dilatation with diarrheic contents.

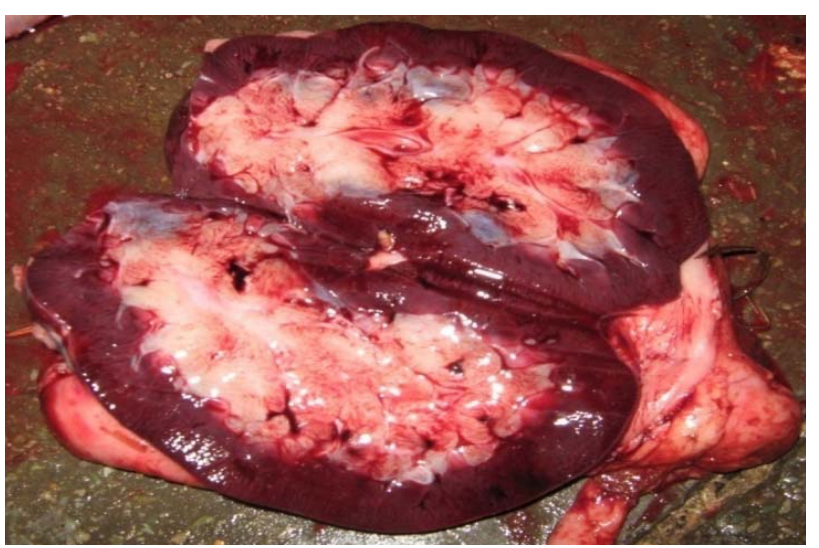

Figure 6. Kidney-marked congestion in cortex. 


\subsection{Histopathology}

Histopatholgically, the lesions were more specific and the common findings in both the animals were congestion, haemorrhages and emphysema in lungs (Figure 7), necrotic enteritis (Figure 8) with mononuclear cell infilteration, congestion and lower nephron nephrosis in kidneys (Figure 9), mild sinusoidal congestion and hepatocellular degeneration (Figure 10), besides focal necrosis in liver. In gall bladder, haemorrhages along with sloughing of mucosa (Figure 11) were also recorded. These findings indicated muti-organ failure as the cause of death in endotoxaemia [4]. The small intestine revealed a very characteristic segmental necrosis of the villi (Figure 8), possibly related to ischemia or marked hypoxia. Morphological and functional damage in human intestinal epithelium has been correlated to induced iNOS synthesis by endotoxin causing increase in epithelial permeability and secretory diarrhea [24].

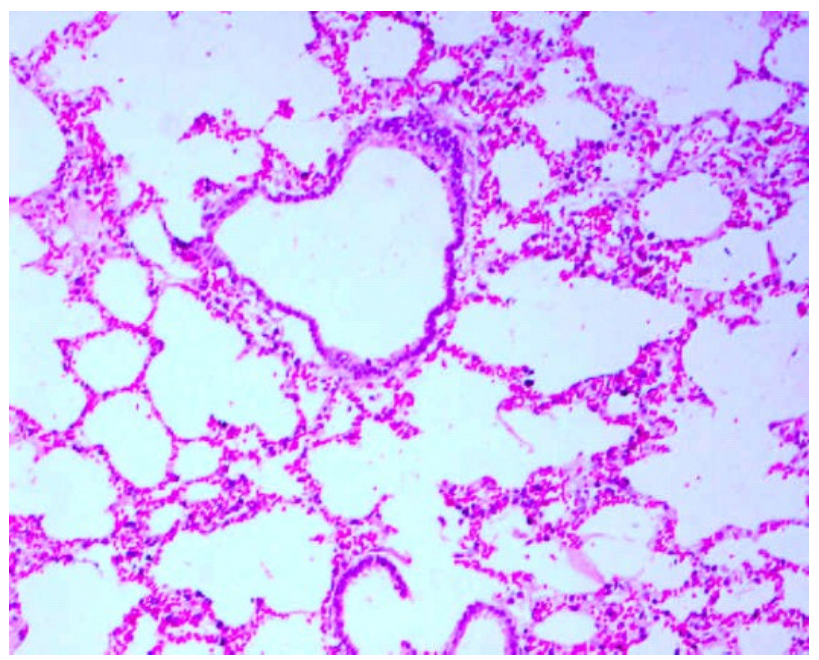

Figure 7. Lung-marked congestion and emphysema (H. E.X150).

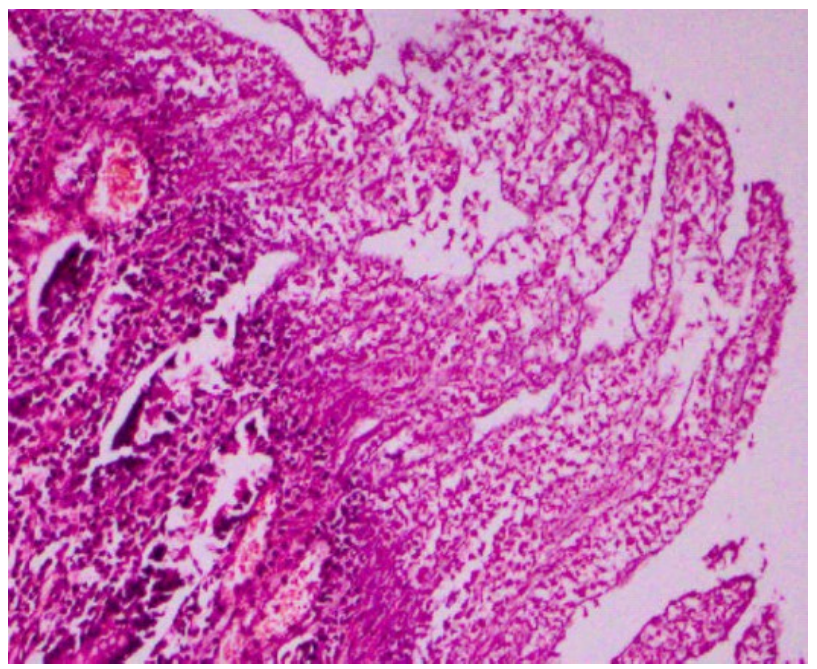

Figure 8. Intestine-necrosis of villi (H. E.X150).

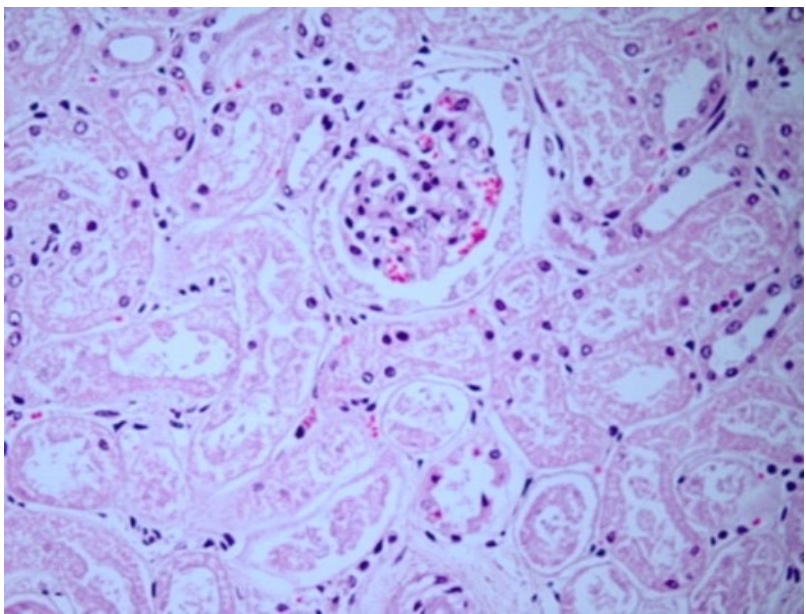

Figure 9. Kidney-diffuse necrosis of tubular epithelium (lower nephron nephrosis) along with congestion in a glomerulus $(\mathrm{H}$. E.X300).

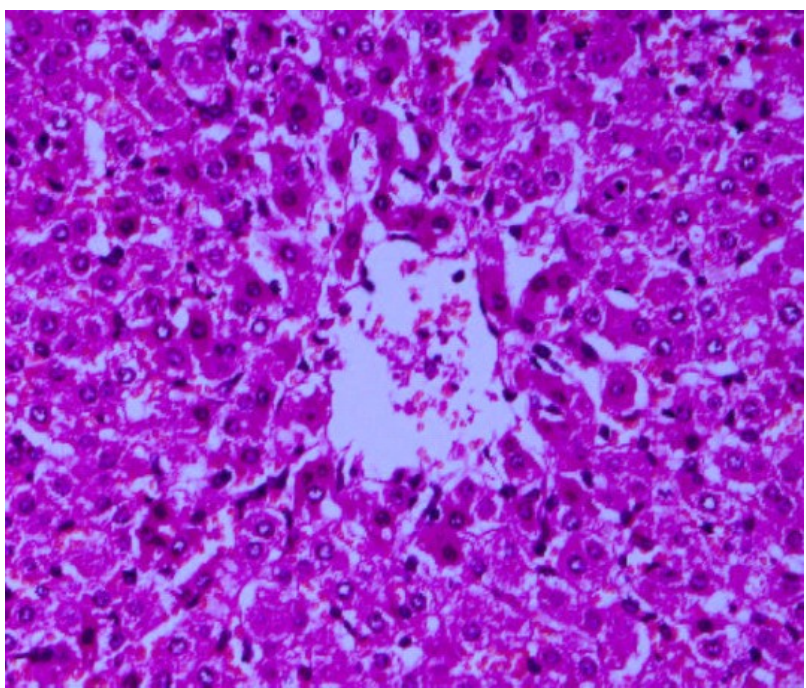

Figure 10. Liver-congestion and mild vacuolar degeneration of hepatocytes (H. E.X300).

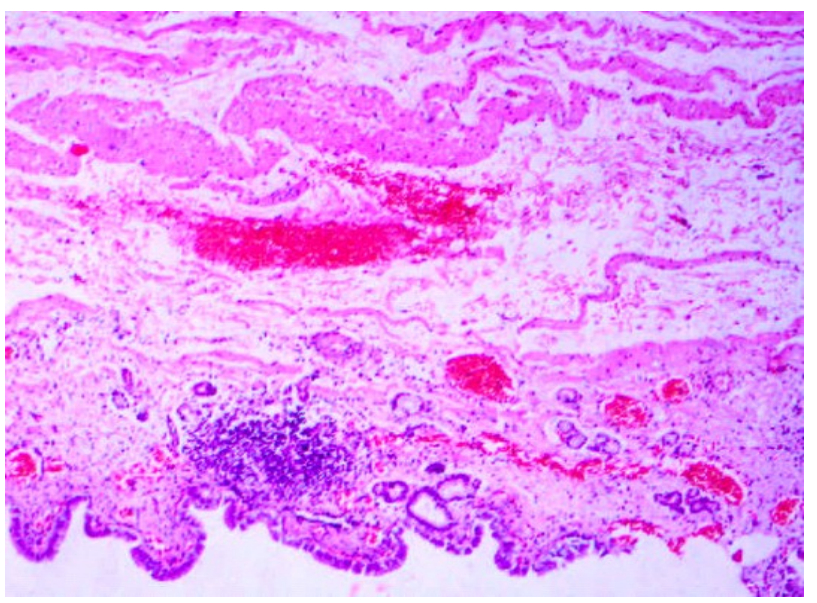

Figure 11. Gall bladder-haemorrhages along with sloughing of mucosa (H.E.X150). 
Atelactasis, congestion, haemorrhages and emphysema in lungs, edema in intestinal mucosa along with extensive coagulative necrosis of epithelial cells of villi, diffuse coagulative necrosis of convoluted tubules of kidney and congestion, haemorrhages with fatty degeneration and coagulative necrosis in liver was previously observed. [25] Edema, congestion and haemorrhages in lungs, nephritic changes in kidney, areas of coagulative necrosis of the hepatocytes and necrosis of the intestinal villi with infiltration of polymorphs was also reported earlier [26].

In one of the endotoxemic buffalo calves, degenerative changes of cardiac myocytes along with mononuclear cell infiltration in perivascular region of the myocardium (Figure 12) were also noticed, suggesting cardiomyopathy. Hackel et al. (1974) [27] reported myocytic necrosis and haemorrhage in the sub-endocardial region of myocardium in endotoxaemia.

In the second buffalo calf, congestion, haemorrhages, neuronal degeneration and mild edema in the cerebrum (Figure 13) indicated endotoxin induced encephalopathy [28]. Nagaraja (1979) [10] and Sokkar (2003) [25] also reported numerous haemorrhages and edema in cerebrum of endotoxemic calves and rams, respectively. These changes were suggestive of toxemia related vascular injury, particularly the haemorrhage in the brain might be of greater relevance.

Fibrinous thrombi in the microvasculature of lungs were also noticed in one buffalo calf (Figure 14). Nagaraja et al. (1979) [10] also observed fibrin thrombi in arterioles and capillaries of lungs in endotoxemic calves. These findings led to the belief that there was setting up of intravascular coagulation. There are considerable interspecies differences in sensitivity to endotoxin, however, humans and ruminants show a relatively similar and

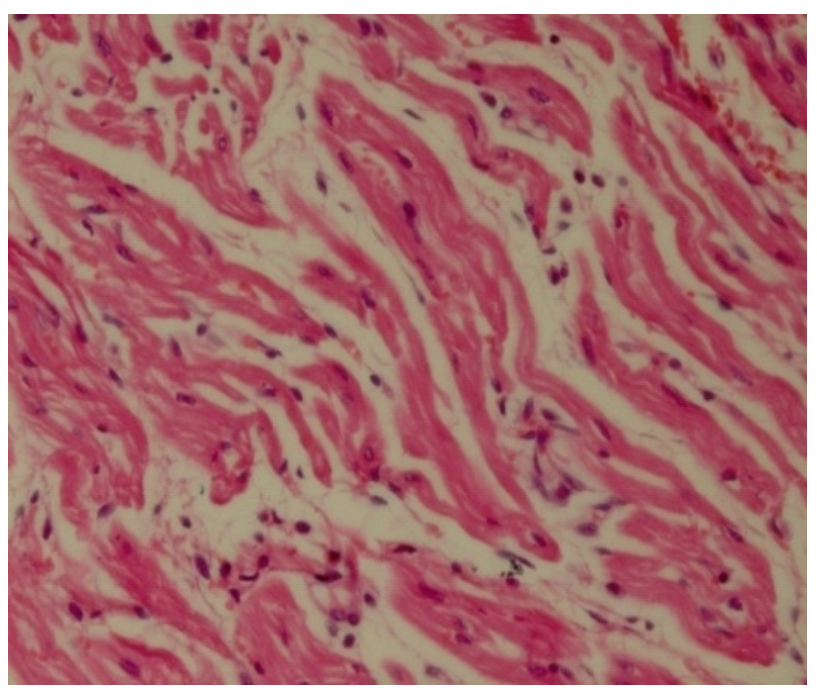

Figure 12. Heart-Mild mononuclear infiltration and degeneration (H.E.X300).

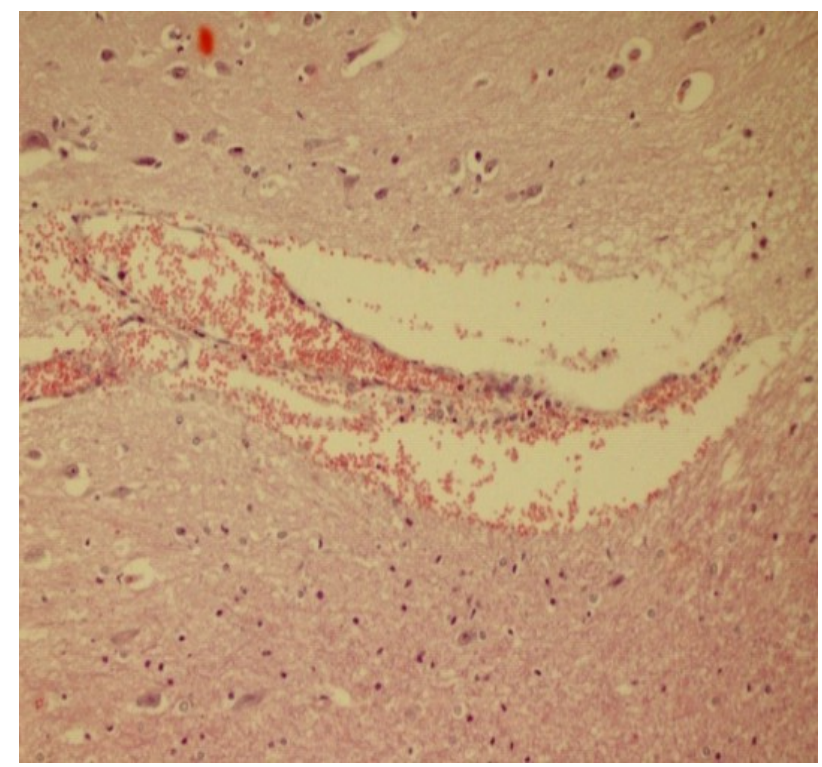

Figure 13. Cerebrum-congestion, haemorrhages, neuronal degeneration and mild edema (H. E.X150).

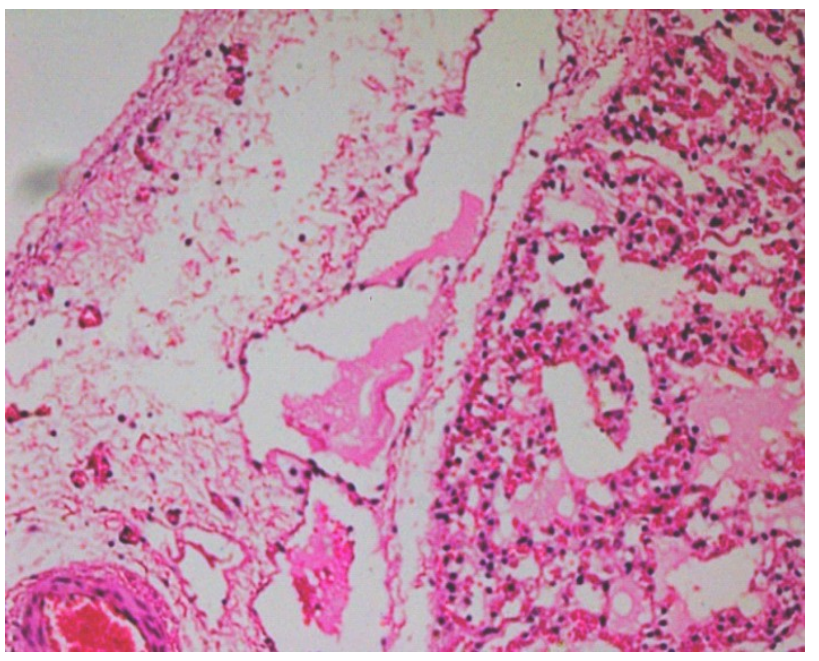

Figure 14. Lung-congestion and fibrinous emboli in vessel (H. E.X75).

enhanced response to endotoxin. Therefore, in the present investigation, bovine was selected as animal model to simulate human endotoxic shock [4].

\subsection{Treatment}

Treatment of endotoxemia is difficult because of the numerous mediators involved. There are three possible approaches in treating endotoxemia. The interaction of endotoxin with target cells can be blocked by inducing tolerance, decreasing plasma endotoxin concentrations, or interfering with endotoxin binding [29]. According to Eicosanoids are responsible for many of the clinical manifestations of endotoxemia [30]. NSAIDS inhibit the production of eicosanoids and TXA-2. Among NSAIDS, flu- 
nixin meglumine is the most effective and is anti-endotoxic at doses much lower than those required for analgesia. Administration of hypertonic saline leads to reentry of extravascular fluids into the vascular compartment to produce a more rapid response and marked haemodynamic effects than conventional use of isotonic solutions [31]. Endotoxemia also leads to protein loss and reduced colloidal oncotic pressure. The use of colloid therapy, including synthetic and natural colloids, is therefore indicated to maintain the colloidal oncotic pressure and to replenish the protein loss [32]. The fluids are critical in the pathogenesis and early resuscitation of septic shock. Administration of fluids especially colloids and crystalloids modulate inflammation, improve micro-vasular perfusion, impact organ function and thereby outcome. The combination of all these factors might have led to survival of 3 out of 5 calves in the present study.

\section{CONCLUSION}

A perusal of clinical signs, clinical chemistry and pathological lesions in dead calves indicated that there is a muti-organ damage and pathologies induced by entotoxic shock are critical for maintenance of life processes. If the damage becomes irreparable, the animal may die. However, constituting timely therapeutic regimens consisting of hypertonic saline solution, dextran-40, flunixin meglumine and whole blood infusion as used in the present study could counter or reverse some of the deleterious effects of endotoxins and thereby save lives.

\section{REFERENCES}

[1] Vincent, J.L. and Backer, D.D. (2001) Patho-physiology of septic shock. Advances in Sepsis, 1, 87-92.

[2] Hodgson, J.C. (2006) Endotoxin and mammalian host responses during experimental disease. Journal of Comparative Pathology, 135, 157-175.

[3] Ng, S.W., Zhang, H., Hedge, A. and Bhatia, M. (2008) Role of preprotachykinin-A gene products on multiple organ injury in LPS-induced endotoxemia. Journal of Leukocyte Biology, 83, 288-295. http://dx.doi.org/10.1189/jlb.0807575

[4] Garrido, A.G., Poli de Figueiredo, L.F. and Silva, M.R. (2004) Experimental models of sepsis and septic shock: An overview. Acta Cirurgica Brasileira, 19, 82-88. http://dx.doi.org/10.1590/S0102-86502004000200001

[5] Thomas, J.S. (2000) Schalm's veterinary haematology. Chapter $13^{\text {th }} .5$ th Edition, Lippincotts Williams and Wilkins, Inc.

[6] Snecdecor, G.W. and Cochran, W.G. (1976) Statistical methods, Iowa state college press. Iowa.

[7] Sobti, V.K., Mirakhur, K.K., Krishnamurthy, D. and Nigam, J.M. (1981) Ringers lactate and homologous blood transfusion in hemorrhagic shock in buffalo calves. Indian Journal of Experimental Biology, 19, 371-374.
[8] Singh, D.V., Singh, R.V. and Sodhi, S.P.S. (2004) Blood biochemical parameters during bovine endotoxemia and after $\mathrm{i} / \mathrm{v}$ infusion of hypertonic saline solution and plasmix-D-40. Indian Journal of Animal Sciences, 74, 10981101.

[9] Kumar, R. (1989) Hormonal and biochemical profile during development and reproductive stages in buffalo calves. MVSc Thesis Punjab Agricultural University, Ludhiana.

[10] Nagaraja, T.G., Bartley, E.E., Anthony, H.D., Leipold, H.W. and Fina, L.R. (1979) Endotoxin shock in calves from intravenous injection of rumen bacterial endotoxin. Journal of Animal Sciences, 49, 567-582.

[11] Singh, K., Krishnamurthy, D. and Peshin, P.K. (1997) Endotoxin shock with and without dexamethasone pretreatment in anaesthetized buffalo calves-II. Indian Journal of Veterinary Surgery, 18, 8-11.

[12] Constable, P.D., Schmall, M., Muir, W.W. and Hoffsis, G.F. (1991) Respiratory, renal, hematological and serum biochemical effects of hypertonic saline solution in endotoxemic calves. American Journal of Veterinary Research, 52, 990-998.

[13] Jean, C.D., Constable, P.D. and Yorchuk, K. (1993) The clinical use of hypertonic saline in food animals with haemorrhagic and endotoxic shock. Agriculture Practice, 14, 6-11.

[14] Singh, D.V. (2000) Physiological and pharmacological studies on bovine endotoxic shock and its treatment. Ph.D. Thesis, Punjab Agricultural University, Ludhiana.

[15] Kaneko, J.J., Harvey, J.W. and Bruss, M.L. (1997) Clinical biochemistry of domestic animals. 5th Edition, Academic Press, New York, pp. 126-134, 622, 893.

[16] Deldar, A., Naylor, J.M. and Broom, J.C. (1984) Effect of E. coli endotoxin on leukocytes, platelets count, fibrinogen concentration in colostrum fed and colostrum deficient neonatal calves. American Journal of Veterinary Research, 45, 670-676.

[17] Ghuman, G.S. and Singh, D.V. (2009) Biochemical profiles during endotoxic shock and after hypertonic saline solution, dexametasone and flunixin meglumine administration in buffalo calves. Toxicology International, 16, 73-76.

[18] Ghuman, G.S. and Singh, D.V. (2009) Biochemical profiles following Flunixin meglumine administration in combination with hypertonic saline during endotoxic shock in buffalo calves. Indian Journal of Animal Sciences, 79, 669-672.

[19] Radostits, O.M., Gay, C.G., Blood, D.C. and Hinchcliff, K.W. (2000) Textbook of diseases of cattle, sheep, pigs, goats and horses. 9th Edition, Chapter II, IX and Appendix, WB Saunders Company Ltd., pp. 41-47, 410, 1820.

[20] Singh, D.V. (1990) Effect of circulatory shock on the cardiovascular system of buffalo calves. M.V.Sc. Dissertation. Punjab Agricultural University, Ludhiana.

[21] Celly, C.S. and Prasad, B. (1987) Changes in plasma, cerebrospinal fluid, urinary and salivary electrolytes during experimental septic shock in calves. Indian Journal of Experimental Biology, 25, 73-74. 
[22] Singh, D.V., Singh, R.V. and Sodhi, S.P.S. (2007) Some biochemical profiles during bovine endotoxic (lipopolysaccharide) shock and after treatment with hypertonic saline solution. Indian Journal of Animal Sciences, 77, 438441.

[23] Singh, D.V., Sodhi, S.P.S. and Singh, R. (1994) Effect of shock in macro and microelements status in Cow and Buffalo Calves. Indian Veterinary Medical Journal, 18, 142-148.

[24] Vincent, J.L., Zhang, H., Szabo, C. and Preiser, J.C. (2000) Effects of nitric oxide in septic shock. American Journal of Respiratory and Critical Care Medicine, 6, 1781-1785.

http://dx.doi.org/10.1164/ajrccm.161.6.9812004

[25] Singh, D.V., Sodhi, S.P.S., Brar, A.P.S. and Grewal, J.S. (1996) Certain pathological profiles of endotoxic shock in buffalo calves. Buffalo Journal, 19, 283-288.

[26] Sokkar, S.M., Darwiesh, G. and Madbooly, A. (2003) Study of the pathological effects of Escherichia coli endotoxin in rams. Journal of Veterinary Medicine, 50, 226230. http://dx.doi.org/10.1046/j.1439-0450.2003.00651.x

[27] Hackel, D.B., Ratliff, N.B. and Mikat, E. (1974) The heart in shock: Brief review. Circulation Research, 35,
805-811. http://dx.doi.org/10.1161/01.RES.35.6.805

[28] Papadopoulos, M.C., Davies, D.C., Moss, R.F., Tighe, D. and Bennett, E.D. (2000) Pathophysiology of septic encephalopathy: A review. Critical Care Medicine, 28, 30113024. http://dx.doi.org/10.1097/00003246-200008000-00057

[29] Hardie, E.M. and Krusse-Elliott, K. (2008) Endotoxic shock Part II: A review of treatment. Journal of Internal Medicine, 4, 306-314.

[30] Moses, V.S. and Bertone, A.L. (2002) Non-steriodal antiinflammatory drugs. Veterinary Clinics of North America: Equine Practice, 18, 21-37. http://dx.doi.org/10.1016/S0749-0739(01)00002-5

[31] Zafar, M.A., Hussain, M.H., Muhammad, G. and Saqib, M. (2004) Potential use of hypertonic saline solution (7-7.5\% Nacl) resuscitation in hypovolemic and endotoxic shock. International Journal of Agriculture and Biology, 6, 926-930.

[32] Kelmer, G. (2009) Update on treatment of endotoxemia. Veterinary Clinics of North America: Equine Practice, 25, 259-270. http://dx.doi.org/10.1016/j.cveq.2009.04.012 